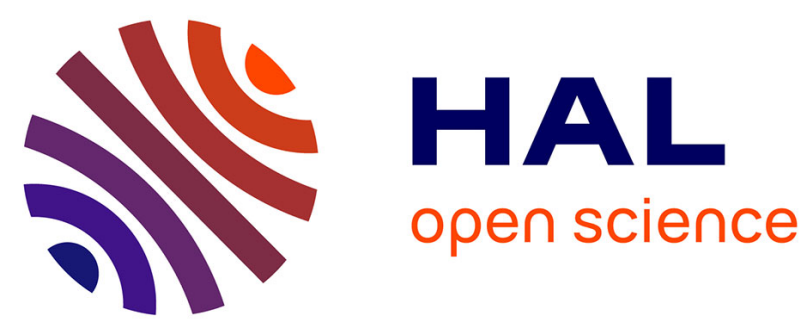

\title{
Developing a Structured Approach to Converging Business Process Management and Customer Experience Management Initiatives Dino Pavlić, Maja Ćukušić
}

\section{- To cite this version:}

Dino Pavlić, Maja Ćukušić. Developing a Structured Approach to Converging Business Process Management and Customer Experience Management Initiatives. 12th IFIP Working Conference on The Practice of Enterprise Modeling (PoEM), Nov 2019, Luxembourg, Luxembourg. pp.151-166, 10.1007/978-3-030-35151-9_10 . hal-03231357

\section{HAL Id: hal-03231357 \\ https://hal.inria.fr/hal-03231357}

Submitted on 20 May 2021

HAL is a multi-disciplinary open access archive for the deposit and dissemination of scientific research documents, whether they are published or not. The documents may come from teaching and research institutions in France or abroad, or from public or private research centers.
L'archive ouverte pluridisciplinaire HAL, est destinée au dépôt et à la diffusion de documents scientifiques de niveau recherche, publiés ou non, émanant des établissements d'enseignement et de recherche français ou étrangers, des laboratoires publics ou privés. 


\title{
Developing a Structured Approach to Converging Business Process Management and Customer Experience Management Initiatives
}

\author{
Dino Pavlić ${ }^{\square[0000-0003-4475-4675], ~ M a j a ~ C ́ u k u s ̌ i c ́ ~[0000-0002-7553-8273] ~}$ \\ Faculty of Economics, Business and Tourism, University of Split, Croatia \\ \{dpavlic, mcukusic\}@efst.hr
}

\begin{abstract}
Both in theory and practice, a lack of a formulated structure to facilitate integrated modeling and analysis of internal business processes and customer experiences external to the organization has been identified by many authors. Tackling this issue, a convergent approach aligning Business Process Management (BPM) and Customer eXperience Management (CXM) initiatives, is proposed in the paper, along with a full set of top-down BPM-CXM models varying in the level of detail. To validate the proposed models, a focus group study with experts in BPM and CXM domains was organized, and the findings are reported and further operationalized using a tool widely used in the EMEA region.
\end{abstract}

Keywords: Focus group, BPM, CXM, Customer journey.

\section{Introduction}

In practice, in the context of Business Process Management (BPM) initiatives, customer orientation often remains a mantra, while process optimization efforts are observed through "inside-out" perspective only, disregarding the customers' perspective. The innovative "outside-in" approach to BPM (by actively involving the customer as in [1]) poses a significant challenge for BPM researchers and experts who are usually focused on process modeling and analysis, as well as for the existing BPM tools and methodologies [2]. Recent research studies stress out the importance of involving customers in internal BP analysis and optimization, as well as in business transformation programs [3-10]. However, there are still a number of problems that lead to BPM and Customer eXperience Management (CXM) initiatives not being aligned in practice, for example [11]: BPM is too oriented on cost reduction and efficiency improvements while ignoring customer interactions; Customer Journey Mapping (CJM) as a part of CXM initiatives is too oriented on customer interactions while ignoring the internal processes of the organization; connections between customer journeys and business processes are not well identified; customer journey maps are not standardized; functional silos are not cooperating well; and the key performance indicators (KPIs) between departments are misaligned. One of the reasons for this misalignment is a lack of a model or a structure for integrated modeling and analyzing of internal business processes and customer 
experiences external to the organization [12-15], a topic that this paper addresses directly. The concept of BPM-CXM convergence has been presented earlier (in [16]) while this paper develops it further and presents the results of its evaluation by experts.

The second section of the paper describes the approach to designing BPM-CXM convergence, taking into account the "outside-in" approach to BPM [1] and building around a well-established BPM lifecycle [17]. It also outlines the feedback from a focus group study that was conducted with the view to demonstrate the feasibility of the concept with experts from the EMEA region. The third section of the paper provides an operationalized top-down view of the convergent approach following the same structure, manifested in several models developed using a tool widely popular in the region. The fourth section of the paper provides plans for further work and concludes the paper.

\section{Designing BPM-CXM Convergence}

\subsection{State-of-Art in BPM-CXM Convergence}

The convergence of BPM-CXM presents a new concept addressed by several authors and papers that point out the need for research in this field, in particular $[8,11,13,15$, 18]. The general idea is that the identification, discovery, analysis, redesign, and control of processes should be performed in convergence with identification, discovery, analysis, redesign, and control of customer experience, and not independently [19]. On the one hand, Gloppen et al. [8] promote the strategic use of customer journeys for innovation and business transformation in particular, while on the other, Kumar et al. [20] emphasize BPM as a key factor in achieving customer satisfaction. To overcome this and change the "traditional" end-to-end approach to business transformation, Richardson (in [1]) proposes using a specific type of targeted modeling of customer touchpoints with the organization, and their analysis and optimization in the context of internal organization. This particular standpoint is favored by the authors of the paper, as demonstrated further in the proposed operationalized, prototyped solution in section 3. By incorporating elements of CXM in the proposed solution, customer journey mapping, in particular, a new "outside-in" modern approach to BPM is implemented.

Apart from identifying the need for a structured approach for BPM-CXM convergence in the available literature, related issues (listed as in, e.g. [11]) were observed by authors of the paper in several business transformation projects in large companies. Consequently, the operationalization and evaluation of BPM-CXM convergence model constitute the main contribution of this research study.

\subsection{BPM-CXM Convergence Concept}

To formulate and structure the BPM-CXM convergence, design science approach is used [21] as a research framework. Standard phases were followed (identification of the problem and motivation, definition of the objectives of a solution, design and development, demonstration, evaluation, and communication) during several workshop events during 2018 when there were multiple iterations of literature analysis, objectives defi- 
nition, and model formulation with BPM experts resulting in a high-level concept (presented in [16]) structured around BPM lifecycle and related descriptions and top-down models. BPM-CXM convergence concept (Fig. 1) was the main starting point for discussions as it is structured in a way that would facilitate integrated analysis of customer experience and internal business processes. In general, customer experience is designed and analyzed by using customer journey mapping (as suggested by [22]), which is used as an input for BPM initiatives - from strategic identification of processes for initiating BPM initiatives, to analysis and optimization of processes [19, 23-27]. BPM-CXM convergence approach should reflect the way customer experience can be perceived and analyzed through the whole BPM lifecycle [28]. That is why the proposed concept lays precisely on those foundations - it is based on standard BPM lifecycle [17], and is developed further and operationalized (as in Section 3). It reflects the focus on the analysis of touchpoints between the internal organization and the customer external to the organization combining best practices from BPM and CXM.

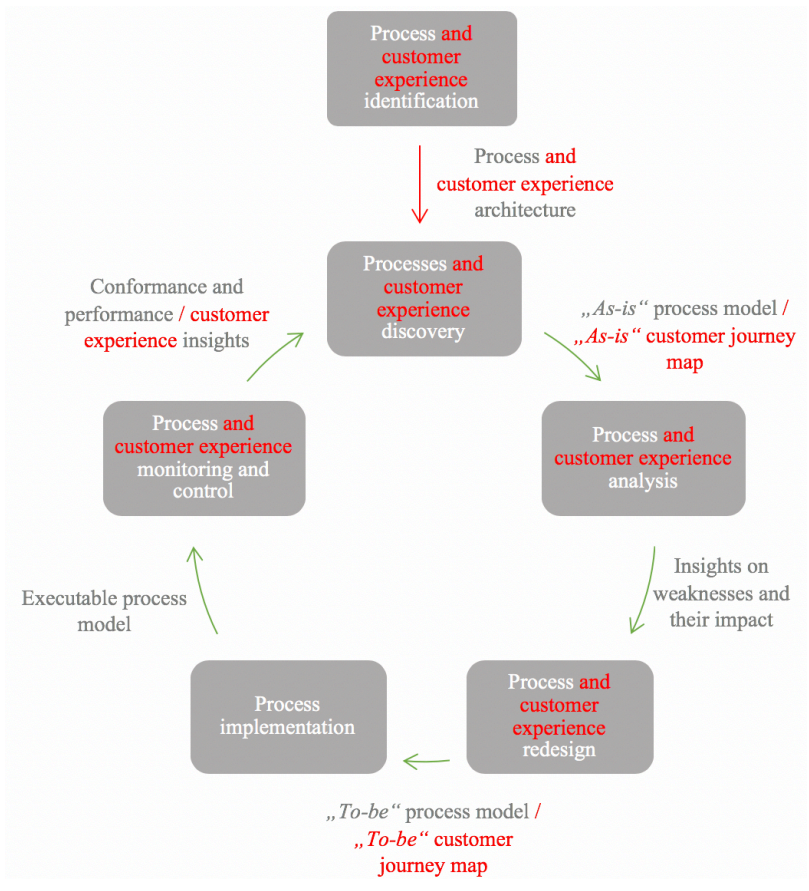

Fig. 1. BPM-CXM convergence concept (based on [1, 17, 28])

\subsection{Evaluation of BPM-CXM Convergence Concept with Experts}

A focus group workshop was organized in March 2019 with the purpose to collect target audience (experts') opinions and attitudes about the proposed convergence concept, related issues and model prototypes. As such, it constitutes an integral part of the design process. Since the required knowledge and experience is very specific, the criteria for expert selection were: at least 10 years of work experience in BPM or CXM projects 
combined, at least two years of experience in each discipline (BPM and CXM projects), regional experience (conducted BPM or CXM projects in at least three countries), and experience in at least three different industries.

Within the network, there were six experts that fit the profile. As all the experts have worked on projects in the EMEA region (primarily in Croatia, Serbia, Bosnia and Herzegovina, and Montenegro), the results of the study reflect their understanding and experience that cannot be easily generalized to other regions. However, in terms of the industries, they have worked in various industries, including finance, gas and oil, local government, transport, logistics, trade, telecommunications, and IT. Basic sociodemographic data about the experts are presented in Table 1.

Table 1. General characteristics of the six experts that participated in the focus group

\begin{tabular}{|l|c|c|l|c|}
\hline & Gender & Education & \multicolumn{1}{|c|}{ Role } & Work experience \\
\hline Expert 1 & Female & MBA & $\begin{array}{l}\text { Head of project } \\
\text { management department }\end{array}$ & 20 years \\
\hline Expert 2 & Male & MCS & BPM consultant & 10 years \\
\hline Expert 3 & Male & MCS & Management consultant & 13 years \\
\hline Expert 4 & Female & MCS & $\begin{array}{l}\text { Head of organization } \\
\text { department }\end{array}$ & 12 years \\
\hline Expert 5 & Male & MCS & Management consultant & 11 years \\
\hline Expert 6 & Female & MBA & Management consultant & 22 years \\
\hline
\end{tabular}

Although the structure of the session was preset, the format was kept flexible, to allow the conversation to develop naturally and to elicit views and opinions. Over the course of three hours, the participants were asked 40 questions split into three parts (Expert background, Current state of BPM \& CXM initiatives, and BPM-CXM convergence approach discussion \& design). The participants were first presented with the focus group purpose and protocol and then were given an overview of the BPM-CXM convergence approach, which included the high-level introduction to the proposed method, as well as all of the operational details (e.g. phases, models, objects, attributes etc.). They were given a short introduction for each question (question examples: Would you adjust the proposed mathematical formula? Would you adjust, edit, or remove any of the elements of the proposed customer journey map?) and enough time to discuss it with other participants and note their individual and consolidated answers. After the focus group, written transcripts by the moderator as well as the participant's notes were analyzed and synthesized in a presentable form.

Within the following paragraphs, consolidated views of the group are presented following the same structure used during the session. Generally, in terms of the problem and motivation of the study, there was a strong consensus, and in terms of the suggestions, all experts contributed considerably and helped to formulate the top-down model prototypes that are presented in section 3 . The choice to present the prototypes in a separate section was made due to two different reasons: to differentiate between the elicited feedback from the experts presented in section 2 and additional (technical) commentary provided by the authors of the paper that accompanies the prototypes in section 3 ; and to provide an operational view on the concept in its entirety. However, the two sections are strongly interrelated with references where appropriate. 


\section{Current State of BPM and CXM Initiatives.}

BPM Initiatives as Enablers of Amazing CX. All experts agree that at the moment, BPM initiatives do not put enough focus on CX. They are missing information about the actual CX and CX KPIs. There is no proper way of getting the real data about the CX and pairing them with the internal process models. BPM experts are too focused on internal business processes, while communication with $\mathrm{CX}$ departments and customers is something that is missing within BPM initiatives. Internal processes are only considered in the context of CXM if a customer is complaining - this is too late since the negative experience already occurred. Overall, there is a consensus that BPM initiatives are not set up as enablers of an amazing CX.

Focus of BPM Initiatives on $C X$. There is agreement that BPM initiatives are only sometimes focused on achieving customer's satisfaction. There is a lack of involvement of the CX departments and customers within BPM initiatives. At this point, BPM initiatives are focused on the internal processes and achieving process excellence without actually considering the external/customer perspective. From a theoretical perspective, BPM initiatives are almost always focused on customer satisfaction; however - in real life, this focus often does not exist.

Customer Focus within Business/IT Transformations. Similarly, experts report that as a part of business/IT transformations, customer focus often remains just a phrase since no CX departments or customers are involved. Customer focus often is the main driver for business/IT transformations however when it comes actually to perform the transformation, the real link between "classic" BPM, CXM, process execution, and performance management is missing. Customers are often a trigger to start an internal process or IT transformation; however, they are not given enough attention during the transformation process itself.

Alignment of BPM \& CXM Initiatives. Experts also agree that BPM and CXM initiatives are not aligned and well-coordinated, and this should be improved. It is mainly due to management vision not being defined in a way to support and encourage the alignment. One of the challenges is in getting the real data from the process execution as well as real data about the customer experience and performing consolidated analysis with internal process data.

Alignment of Goals and KPIs of BPM \& CXM Departments. Furthermore, BPM and CXM departments are considered as not aligned by experts. BPM and CXM departments usually have a completely different strategy, goals, and KPIs.

Communication Between BPM \& CXM Departments. Another issue regularly observed by the experts is that BPM and CXM departments do not communicate regularly, and they see this would need large improvement. Quality of communication between BPM and CXM departments should be improved as well.

BPM-CXM Convergence Approach Discussion and Design.

Structure of BPM \& CXM Lifecycle. Experts find that the proposed BPM-CXM concept (presented Fig. 1) is well structured to support the BPM and CXM convergence considering that CX is introduced as a part of BPM lifecycle. 
CX Landscape Positioning Within the Virtual Organization Model. As a part of the "virtual organization" (a term used to denote entry-level models in BP repositories), business process landscape and CX landscape provide a clear entry point to the more detailed models (top-down approach). It was agreed that Customer experience should be placed within a new, separate quadrant of a virtual organization (as further operationalized in entry-level model prototype in section 3).

Scoring the Overall Customer Experience of Customer Journey. Experts suggest that the overall customer experience of a customer journey should be calculated as an average of overall customer experiences on each touchpoint, which is a part of the individual journey. They propose to build a script for automatic calculation within a BPM tool.

Elements, Attributes, and Color Coding of a Customer Journey Landscape. Attribute naming and color-coding of a customer journey landscape model (presented in section 3 ) were evaluated as clear and appropriate. Elements and attributes of customer journey landscape were also assessed as well structured. It was proposed and agreed that the overall customer experience of a customer journey landscape should be calculated as an average of overall customer experiences on each customer journey, which is a part of the customer journey landscape.

Elements, Attributes, and Color Coding of a Customer Journey Map. Attribute naming and color-coding of a customer journey map (model presented in section 3) were also evaluated as clear and appropriate. Elements and attributes of a customer journey map were assessed as well-structured. As an addition to the proposed elements of the customer journey maps, input/output data/cluster were suggested to be added. Within customer journey maps, it was suggested that color indication of the overall experience should be visible on individual touchpoints, as well as customer journey steps. Touchpoints are the "real" connection between the internal organization and the customer external to the organization, and therefore are more relevant for scoring representation.

Customer Journey Landscape and Customer Journey Map Ownership. The experts suggested that customer journey owners and business process owners should be separated, like front-end and back-end in software development, however, that they should communicate regularly to make sure their goals are aligned. Also, there could be separate ownership roles for customer journeys and customer journey landscapes. Considering that the customer journey owner should enforce the will of the customer within the internal business processes, customer journey owner and business process owner should not be the same person and should align and communicate regularly.

Elements, Attributes, and Color Coding of a Customer Touchpoint Allocation Diagram. Elements and attributes of customer touchpoint allocation diagrams were assessed as well-structured. Attribute naming and color-coding of a customer touchpoint allocation diagram are also considered clear and appropriate. Out of 2 proposed options, option 2 of the proposed touchpoint allocation diagram was selected as preferred one by experts and is presented in section 3. It was agreed that customer experience of the individual touchpoint should be calculated by considering the customer feeling and adding a weighting factor/ponder (importance to the customer).

Setting up an Indication of Customer Experience Related to Certain Internal Business Processes. Overall customer experience linked to an internal business process was 
agreed to be calculated as an average of customer experience of each touchpoint that is a part of the individual internal business process. Also, the script for automatic calculation would be then necessary to be developed and implemented within a BPM tool in order to represent the impact that certain internal business processes have on positive or negative customer experience. The script could be triggered on an hourly basis.

Establishing a Link Between the BPM and CXM Initiatives by Indicating the Customer Experience Levels on Value Added Chain Diagrams. Proposed value-added chain diagram which includes customer experience layers and indication (as in section 3), experts agree, would bring various benefits in terms of BPM-CXM alignment compared to the standard value-added chain diagram. By using the proposed method, they agree that there would be a clear link established between the BPM \& CXM initiatives, BPM initiatives would be more focused on the customer, and internal resources would be spent more optimally. Also, by using the proposed method and formula within the value-added chain diagrams indicating the associated customer experience, focus on the experience while analyzing the internal business process would be achieved. An internal business process model, value-added chain, which includes the information and indication on the status of customer experience, is found to be the most beneficial part of the proposed BPM-CXM approach.

Benefits of the Proposed BPM-CXM Convergence Approach. Here, experts confirmed and found multiple benefits of including customer touchpoints within both high level and detailed internal business process models. They believe that the proposed methodology ensures better process optimization as it would combine both internal and external views on the process. Furthermore, it would ensure better alignment between the classical BPM and CXM approaches. BPM-CXM convergence would ultimately lead to focusing BPM initiatives on those business processes which would have the greatest impact on CX improvement. It would point out that everything that a company or its resources do affect the customer. Internally, the customer would "become alive" as experts state. The proposed approach would enable customer-experience-driven internal business process optimizations as well as achieving true customer focus. It would ensure better alignment between the internal and external view on the processes, thus helping to optimize the processes that would ultimately serve customers in a better way.

Indicators to Measure the Effectiveness of BPM-CXM Approach. The effectiveness of the proposed BPM-CXM approach was suggested to be measured through the improvement of customer satisfaction. Also, another way to measure would be through the number of detected pain points related to internal business process, number of detected positive experiences related to internal business process, number of eliminated pain points due to the internal business process optimization.

Pitfalls of the Proposed Convergence Approach. No significant pitfalls of the proposed approach were detected. However, one potential shortcoming was identified - the experts emphasized that the ownership roles are not clear enough. It could lead to inadequate governance of BPM-CXM convergent approach. Another aspect that was emphasized as important in considering and implementing the proposed structure was the frequency of the processes that should be considered within the analysis. 


\section{Proposing the Set of Models for BPM-CXM Convergence}

To demonstrate and operationalize the concepts presented above, and to provide a functioning and structured convergent approach that could be used in practice, a number of model prototypes were developed and evaluated with experts during the course of the focus group, and are presented in this section. These model prototypes are mapped to ARIS Value Engineering (AVE) methodology and ARIS platform [29] due to the popularity of the methodology and tool in the region.

\subsection{Structuring the Models Around the BPM Lifecycle}

The models are structured around the lifecycle [17] phases (as already illustrated in Fig. 1): (1) Internal business processes and customer experience are identified by defining process and CX landscapes within the "virtual organization". They are mapped on a high level; the top-down approach is used. (2) Discovery phase includes mapping of asis business process models and customer journey maps. It also includes setting up customer touchpoints as a part of customer journey maps, as well as internal business processes. (3) Analysis phase includes analysis of internal business processes and customer journeys, with a focus on the analysis of customer touchpoints. The analysis phase is greatly impacted by the new approach since it includes an indication on the level of overall customer experience being positive or negative concerning the internal processes. (4) According to these findings and the analysis performed, processes and customer journeys redesign is performed. (5) Process implementation and (6) processes and customer journeys monitoring close the (iterative) model lifecycle.

\subsection{Overview of Top-Down BPM-CXM Convergent Models in BP Repository}

Entry-level model. Entry-level model (Fig. 2) (also called "start model" or "overview model" [30]), in addition to five "standard" virtual organization elements as proposed by AVE methodology (organizational view, data view and other), now contains CX landscape included in a separate quadrant.

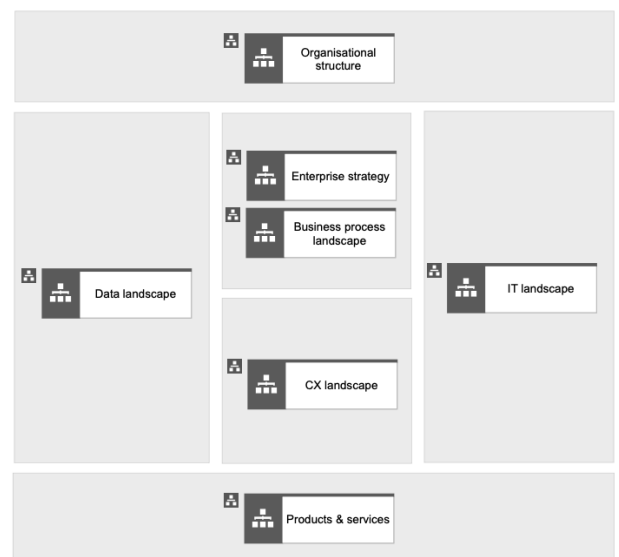

Fig. 2. A prototype of the new entry-level model 
This way, a virtual organization or entry-level model includes the same level of details for both internal business processes and customer experience. On this (top) level of detail, both internal business processes and customer experience are represented as a landscape. When clicked on any of the two landscapes, more detailed models are opened.

Customer Journey Landscape. In a more detailed representation, customer lifecycle stage, and customer journeys, which are a part of the specific lifecycle are represented (Fig. 3). Overall customer experience (CX) attribute of a Customer lifecycle stage is proposed to be calculated as an average of Overall customer experience (CX) of all customer journeys connected to it. Overall customer experience (CX) attribute of both Customer lifecycle stage and Customer journey objects are used as a basis for colorcoding of those objects. The proposed method to calculate a value of a customer experience for a single customer journey is described in the next section. The Overall customer experience (CX) falls into ranges unanimously agreed by the experts: 6 to 10 (Very good, i.e. 5), 2 to 5.99 (Good, i.e. 4), -2 to 1.99 (Neutral, i.e. 3), -6 to -1.99 (Bad, i.e. 2), -10 to -5.99 (Very bad, i.e. 1) while the respective stage/journey color-coding is green for very good (5), yellow for good (4), grey for neutral (3), orange for bad (2) and red for very bad (1). On the customer lifecycle stage level, Customer lifecycle stage owners can be defined as an object attribute. Descriptions can be added as a model/object attribute.

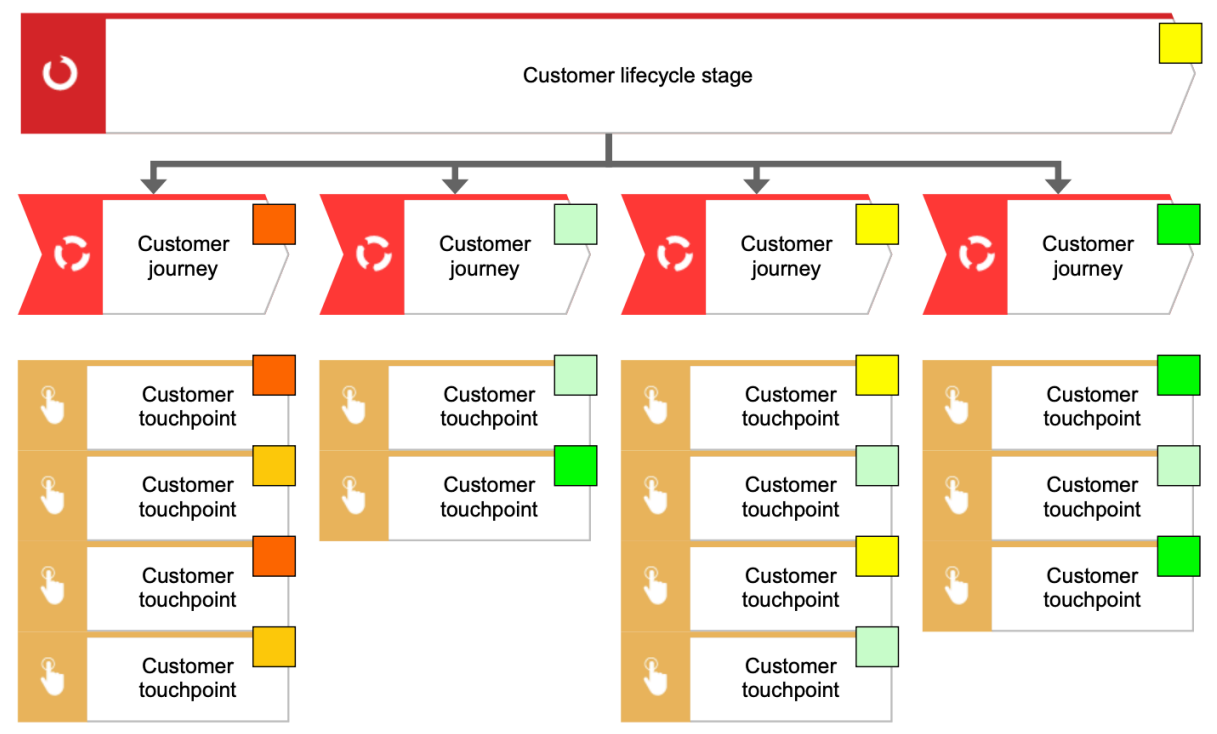

Fig. 3. A prototype of the new customer lifecycle stage model

Customer Journey Map. The model (Figure 4) is composed of various elements describing the journey: customer journey steps, customer touchpoints, channels, inputs, outputs, risks, KPIs, initiatives, ownership, internal process step. Each touchpoint contains a description and customer journey owners are defined as a model attribute. 


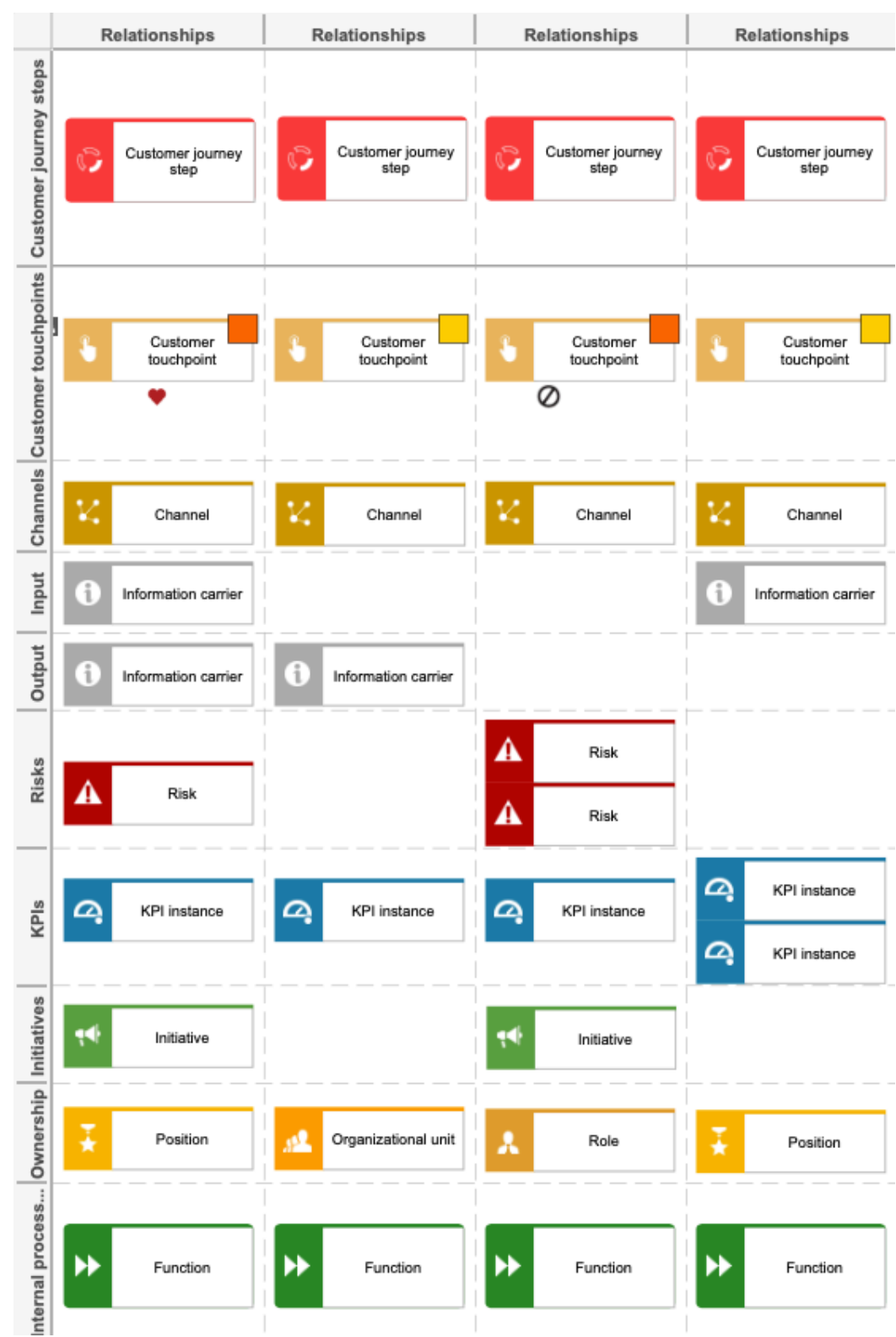

Fig. 4. A prototype of the new customer journey map

To calculate the Overall customer experience $(C X)$ attribute of Customer journey object, each touchpoint within the journey (Figure 4) is taken into consideration. The overall customer experience (CX) of a Customer journey is calculated as an average of Overall customer experience (CX) attributes of all touchpoints within the journey. Attributes which are relevant for calculation within the touchpoints are Importance to 
customer (CX) (5 - very high, 4 - high, 3 - neutral, 2 - low, and 1 - very low) and Customer feeling (CX) (2 - very good, 1 - good, 0 - neutral, -1 - bad, -2 - very bad). The data is based on existing KPIs, or comes from different systems, and research.

Overall customer experience (CX) of each individual touchpoint is calculated in a following way: Customer feeling (CX) on Touchpoint $\mathrm{X} *$ Importance to customer (CX) on Touchpoint X. Overall customer experience $(C X)$ and Overall customer experience $(C X)$ attributes are used for grading and color-coding in the same way as explained earlier. Each touchpoint can be (optional) a pain point, moment of truth, and best practice. Those three are represented with icons below touchpoints. Customer touchpoints which are also pain points are expected to have Customer feeling (CX) of Very bad (1), while Customer touchpoints which are also moments of truth are expected to have Importance to customer (CX) of Very high (5).

Customer Touchpoint Allocation Diagram. Customer touchpoints are analyzed in detail by using the Customer touchpoints allocation diagram, containing various standard elements presented in Figure 5. Elements which describe a certain touchpoint include: customer journey steps, channels, inputs, outputs, ownership, risks, KPIs, initiatives, and internal process step.

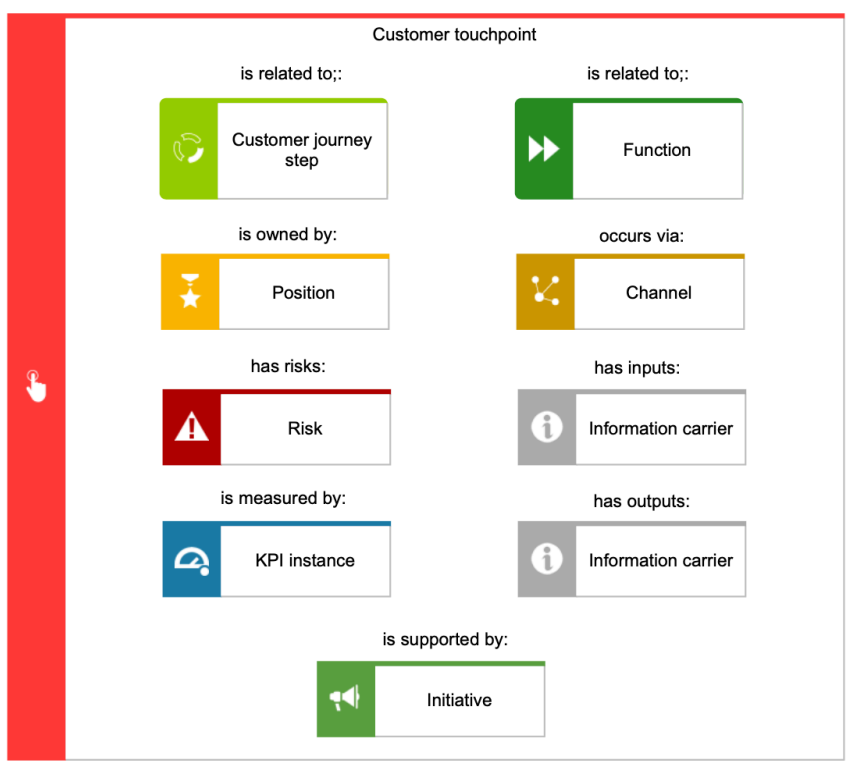

Fig. 5. A prototype of the new customer touchpoint allocation diagram

Value-added Chain Diagram. From the internal business process perspective, highlevel business processes are represented by using the value-added chain diagrams (Figure 6). They include a color indication of the Overall customer experience (CX), which is related to the individual process. They also include customer experience (touchpoints) layer. Based on the relation between the individual touchpoints (which are a part of certain Customer journey) with internal business process steps (which are a part of a certain Value-added chain diagram), the calculation is performed to determine 
which internal business processes (on a value-added chain level) have the best/worst customer experience. According to this, recommendations are given on which internal business processes should be modified in order to improve customer experience most effectively. The Overall customer experience $(C X)$ on internal business process level is calculated as an average of Overall customer experience (CX) of all Customer touchpoints which are a part of the underlying internal business process model. The Overall customer experience $(C X)$ of the end-to-end value-added chain (higher level internal business process) is calculated as an average of all connected underlying value-added chains. The same color-coding principle is used as presented earlier within this paper. Optionally, the number of process instantiations and/or revenue per each sub-process (value-added chain) can be added in order to add value to the analysis.

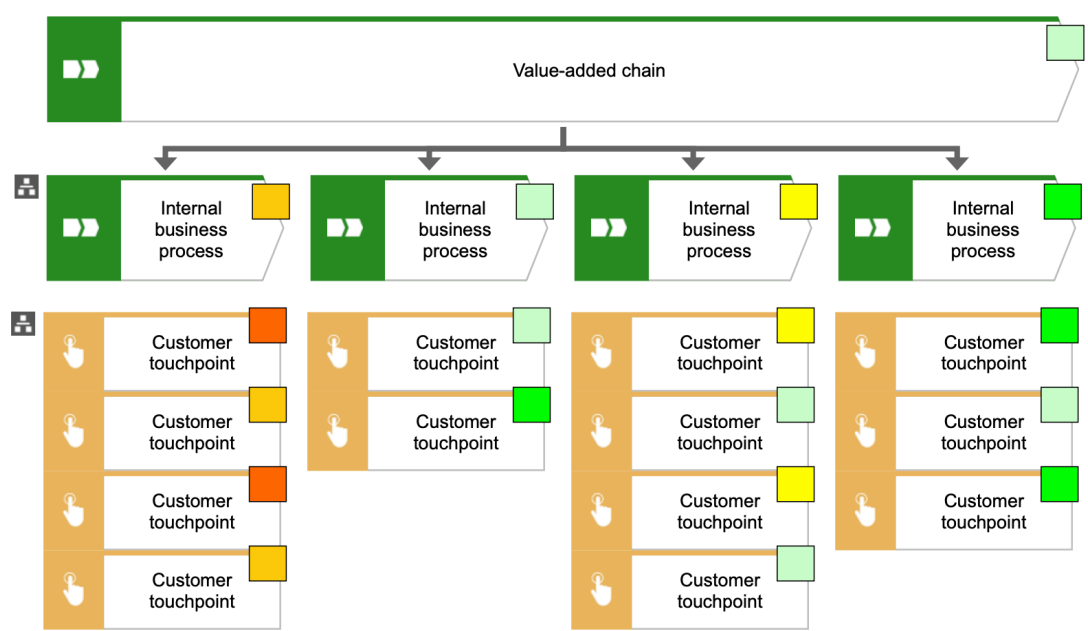

Fig. 6. A prototype of the new value-added chain diagram (with touchpoint representation)

Event-Driven Process Chain. On a detailed level, internal business processes are represented by using the event-driven process chain diagrams (EPC), Figure 7.

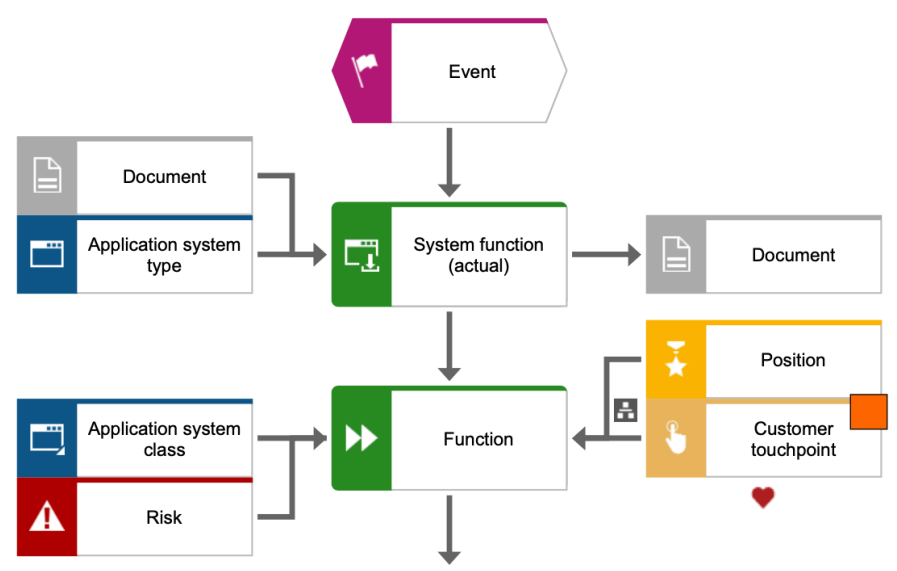

Fig. 7. A segment of the prototype of the new process model (with touchpoint representation) 
Other than the "regular" elements of an internal business process model, they also contain customer touchpoints to represent the customer interactions with the internal organization as well as the with the internal process steps. Touchpoints include a color indication of the overall customer experience following the same color-coding principle as above.

\section{Conclusions and Planned work}

This paper presented an effort to structure and design a BPM-CXM convergence approach. It is focused on the design itself - problem definition and solution proposal and development, which was presented and evaluated with a group of experts with substantial experience in BPM and CXM fields in the EMEA region. The main deliverable of this phase of the research is the verified and operationalized version of the BPM-CXM structured convergence approach, including the prototype models and recommendations for their use. Based on the feedback from the field received so far, it is expected that this research will influence BPM and CXM disciplines by proposing a convergence approach, but also the BPM systems used in practice to conduct BPM projects. There are specific plans by several of the experts that participated in the focus group to follow the proposed approach in delivering their future consulting projects should some preconditions be fulfilled (such as customer motivation, level of engagement of teams from both BPM and CXM departments, freedom to use the methodology of own choosing) but they are also waiting for the implementation evidence. On that note, a new phase of the evaluation of the proposed approach would include implementation in a real-life setting in order to further test the feasibility and value of the proposed convergence approach. The implementation and a follow-up evaluation through in-depth interviews with international experts in BPM and CXM fields that participate in the project are in progress. The findings would be used to adjust the proposed work if necessary, detect issues, and measure the effects of the new approach. In-depth interviews to evaluate the benefits of using the proposed approach compared to the traditional BPM and CXM approached will specifically evaluate the effects of BPM-CXM convergence approach on the internal organization, alignment of business processes of an internal organization with the needs of the customer, and the customer experience itself.

Multiple benefits from following the proposed approach are expected compared to traditional BPM approaches. The expected effects would include the following: reduction of emphasis on internal business process mapping or "modelling because of modelling" within the BPM initiatives, reduction of functional silos effect and better alignment between the organizational departments, improved coordination between the organizational departments in defining the key performance indicators, increase of innovation level in organizations, design of business processes which take the interactions with the customer into the account and enable customer expectations fulfilment, development of products and services that are really needed by the customers, rational usage of organizational resources and more. 
After validating the theses in a real-life setting, it is expected that the results will influence BPM and CXM disciplines by proposing a new version of the structured convergence approach and instructions for its implementation, but also the BPM systems used in practice as these will need adjustments in terms of available models, objects and methods as demonstrated in the paper.

Acknowledgment. This work is supported by the Croatian Science Foundation [grant number HRZZ-UIP-2017-05-7625].

\section{$5 \quad$ References}

1. Schooff P (2016) End of the Road for End-to-End Process Transformation. Interview with Clay Richardson. In: BPM Today blog, http://bpm.com/bpm-today/blogs/1136-end-of-theroad-for-end-to-end-process-transformation. Accessed 26 July 2019.

2. Bergh J Van Den, Thijs S, Viaene S (2014) Transforming Through Processes Leading Voices on BPM, People and Technology. Springer International Publishing, London. doi: 10.1007/978-3-319-03937-4

3. Gersch M, Hewing M, Schöler B (2011) Business Process Blueprinting - an enhanced view on process performance. Bus Process Manag J 17(5):732-747. doi: 10.1108/14637151111166169

4. Trkman P, Mertens W, Viaene S, Gemmel P (2015) From business process management to customer process management. Bus Process Manag J 21(2):250-266. doi: 10.1108/BPMJ02-2014-0010

5. Neubauer T (2009) An empirical study about the status of business process management. Bus Process Manag J 15(2):166-183. doi: 10.1108/14637150910949434

6. Schmiedel T, Vom Brocke J, Recker J (2014) Development and validation of an instrument to measure organizational cultures' support of Business Process Management. Inf Manag 51(1):43-56. doi: 10.1016/j.im.2013.08.005

7. Johnston R, Kong X (2011) The Customer Experience: A Road Map for Improvement. Man Ser Qual: An International Journal 21(1):5-24. doi: 10.1108/09604521111100225

8. Gloppen J, Lindquister B, Daae H-P (2016) The customer journey as a tool for business innovation and transformation. In: DeFillippi R, Rieple A, Wikström P (eds) International Perspectives on Business Innovation and Disruption in Design. Edward Elgar Pub. 118-138.

9. Becker J, Niehaves B, Malsbender A, et al (2011) Taking a BPM Lifecycle View on Service Productivity: Results from a Literature Analysis. Proceedings of the XXI International RESER Conference, Germany. https://www.researchgate.net/publication/267298145_Taking_a_BPM_Lifecycle_View_on Service_Productivity_Results_from_a_Literature_Analysis Accessed 26 July 2019.

10. Norton DW, Pine II BJ (2013) Using the customer journey to road test and refine the business model. Strateg Leadersh 41(2):12-17. doi: 10.1108/10878571311318196

11. Straßer J (2016) Aligning Customer Journey Management with Business Process Management. Masters Thesis, University of Amsterdam

12. Surbakti FPS (2015) Customer Process Management: A Systematic Literature Review. Eng Manag Res 4:1-8. doi:10.5539/emr.v4n2p1

13. Følstad A, Kvale K, Halvorsrud R (2014) Customer journeys: Involving customers and internal resources in the design and management of services. Proceedings of the Fourth Service 
Design and Innovation conference, 412-417. http:// ep.liu.se/ecp/099/042/ecp14099042.pdf Accessed 26 July 2019.

14. Bergh J Van Den, Thijs S, Isik Ö, Viaene S (2012) The World Is Not Enough: Customer Centricity and Processes. Bus Process Trends 1-7. https://www.bptrends.com/the-world-isnot-enough/ Accessed 26 July 2019.

15. Hewing M (2014) Business process blueprinting: A method for customer-oriented business process modeling. Springer Gabler, Berlin. doi: 10.1007/978-3-658-03729-1

16. Pavlić, D., Ćukušić, M. (2019) Conceptualizing the convergence model of business process management and customer experience management. In Proceedings of BPM Blockchain and Central and Eastern Europe Forum. LNBIP. In print.

17. Dumas M, La Rosa M, Mendling J, Reijers HA (2018) Fundamentals of business process management. Springer-Verlag Berlin Heidelberg, Berlin. doi: 10.1007/978-3-662-56509-4

18. Rosenbaum MS, Otalora ML, Contreras Ramírez G (2017) How to create a realistic customer journey map. Bus Horiz 60(1): 143-150. doi:10.1016/j.bushor.2016.09.010

19. Davis R (2011) It's the Customer Journey That Counts. BPTrends Column, 1-5. https://www.bptrends.com/processes-in-practice-its-the-customer-journey-that-counts/ Accessed 26 July 2019.

20. Kumar V, Smart P a., Maddern H, Maull RS (2008) Alternative perspectives on service quality and customer satisfaction: the role of BPM. Int J Serv Ind Manag 19(2):176-187. doi: 10.1108/09564230810869720.

21. Peffers K, Tuunanen T, Rothenberger MA, Chatterjee S (2007) A design science research methodology for information systems research. J Manag Inf Syst 24(3):45-78. doi: 10.2753/MIS0742-1222240302

22. Lemon, K. N., Verhoef, P. C. (2016) Understanding Customer Experience Throughout the Customer Journey. J of Mrktg, 80(6): 69-96. doi: 10.1509/jm.15.0420

23. Vanwersch RJB et al. (2015) A Critical Evaluation and Framework of Business Process Improvement Methods. Bus Inf Syst Eng (2016) 58: 43. doi: 10.1007/s12599-015-0417-x

24. Moormann J, Palvolgyi EZ (2013) Customer-Centric Business Modeling: Setting a Research Agenda, 15th Conference on Business Informatics. 173-179. doi: 10.1109/CBI.2013.33

25. Flint DJ, Larsson E, Gammelgaard B, Mentzer JT (2005) Logistics innovation: A customer value-oriented social process. J Bus Logist 26:113-147. doi:10.1002/j.21581592.2005.tb00196.x

26. Chen H, Daugherty PJ, Landry TD (2009) Supply chain process integration: A theoretical framework. J Bus Logist 30:27-46. doi: 10.1002/j.2158-1592.2009.tb00110.x

27. Lee C-H, Huang SY, Barnes FB, Kao L (2010) Business performance and customer relationship management: The effect of IT, organisational contingency and business process on Taiwanese manufacturers. Total Qual Manag Bus Excell 21:43-65. doi: $10.1080 / 14783360903492595$

28. Ruland Y (2016) Customer experience and its potential to extend business process management. Master thesis - UHasselt, http://hdl.handle.net/1942/22258

29. Software AG product website. https://www.softwareag.com/in/products/aris_alfabet/bpa/aris_architect/default.html Accessed 26 July2019.

30. Davis, R., Brabander, E. (2007) ARIS Design Platform: Getting Started with BPM. Springer. 